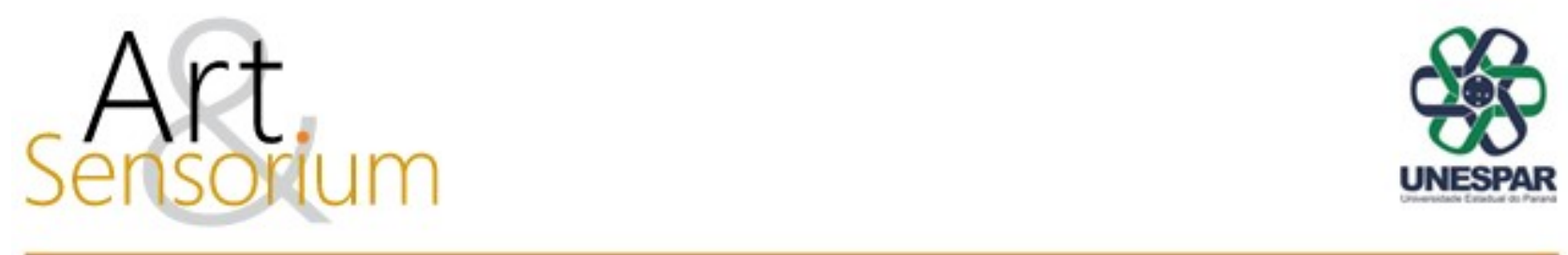

\title{
EM MEIO A NATUREZA, FORA DO CORPO, PURA IMAGEM
}

DOI: https://doi.org/10.33871/23580437.2021.8.2.261-270

Sandra Maria Correia Favero ${ }^{1}$

\begin{abstract}
RESUMO: O ensaio visual, Em meio a natureza, fora do corpo, pura imagem, apresenta uma série de sete fotografias compondo a foto performance realizada junto a vegetação que cerca a casa da artista. A sua interação com um espelho gravado, ora evidenciando, ora ocultando sua própria imagem, tem por intenção enunciar que assim como tudo na natureza, as transformações físicas acontecem conosco, somos mutantes, não somos perenes.
\end{abstract}

Palavras-chave: ensaio visual; espelho; foto performance; natureza.

\section{IN THE MIDDLE OF NATURE, OUT OF THE BODY, PURE IMAGE}

\begin{abstract}
The visual essay, In the middle of nature, out of the body, pure image, presents a series of seven photographs that make up the photo performance taken in the vegetation surrounding the artist's house. Its interaction with an engraved mirror, sometimes showing, sometimes hiding its own image, is intended to enunciate that, like everything else in nature, physical transformations happen to us, we are mutants, we are not perennial.
\end{abstract}

Keywords: visual essay; mirror; photo performance; nature.

\section{EN MEDIO DE LA NATURALEZA, FUERA DEL CUERPO, IMAGEN PURA}

RESUMEN: El ensayo visual, En medio de la naturaleza, fuera del cuerpo, imagen pura, presenta una serie de siete fotografías que conforman la performance fotográfica realizada en la vegetación que rodea la casa del artista. Su interacción con un espejo grabado, a veces mostrando, a veces

\footnotetext{
${ }^{1}$ Universidade do Estado de Santa Catarina (UDESC), Doutorado no Programa de Pós-Graduação em Artes Visuais da Escola de Comunicação e Artes da USP, área de concentração Poéticas Visuais, linha de pesquisa Processos de Criação em Artes Visuais(2015); Mestrado em Engenharia de Produção pela Universidade Federal de Santa Catarina, área de concentração Gestão do Design e do Produto, (2003); Graduação em Bacharelado em Pintura pela Escola de Música e Belas Artes do Paraná, (1979). Atualmente é professora efetiva da UDESC - Centro de Artes, Departamento de Artes Visuais, Graduação e Pós-Graduação, Linha de Pesquisa Processos Artísticos Contemporâneos, ênfase em Gravura, atuando principalmente nos seguintes temas: gravura, memória, natureza, caminhadas, poéticas contemporâneas. Linguagens artísticas: gravura; livro de artista; instalação. Integra o Grupo de Pesquisa Articulações Poéticas vinculado a UDESC. Florianópolis, SC, Brasil. http://lattes.cnpq.br/1656023214349642. https://orcid.org/0000-0002-3730-488X. sandrafavero@gmail.com
} 
ocultando su propia imagen, pretende enunciar que, como todo lo demás en la naturaleza, nos suceden transformaciones físicas, somos mutantes, no somos perennes.

Palabras clave: ensayo visual; espejo; performance fotográfica; naturaleza.

Um espelho antigo com uma moldura de madeira decorada com elementos orgânicos em gesso recoberto por uma tinta dourada já carregada de pó há anos, caiu. A moldura partiu, o gesso quebrou, mas o espelho em forma elíptica permaneceu intacto. Pensei, e agora? Deixei o espelho, este objeto instigante que nos possibilita a "experiência da duplicação" (COCCIA, 2010, p.21) sobre a mesa do ateliê. Ao esfarelar o papel colado ao fundo, enxerguei as camadas que dão ao vidro o poder da reflexão, e encontrei ali, semelhanças com a camada de verniz de proteção usada na gravura em metal, e mais abaixo dela, uma camada dourada que relacionei com o latão. Gravei sobre aquela superfície de camadas, tirando partido da transparência do vidro e da opacidade dourada e betuminosa, pensei naquilo que poderia ser visto ou sugerido nas frestas que se abriam e fui em frente, riscando e dando forma, com mais força ou menos pressão até chegar a um estágio de esgotamento das intenções. Ao testar o que podia ser visto com aquele objeto/lâmina frágil de vidro espelhado, de um lado a transparência e do outro a opacidade, vi a minha imagem ora refletida, ora encoberta, e decidi seguir adiante: dar ao objeto sentidos a mais, além de sua função anterior.

Em consonância com a fotógrafa que acompanha meu processo artístico, decidi fazer registros fotográficos no espaço externo a minha casa, "uma porção de mundo que tem uma relação particular com meu corpo, uma espécie de extensão" (COCCIA, 2018, p.38) onde a natureza se manifesta com liberdade, ou seja, sem controle paisagístico, e onde o meu corpo poderia ser transformado em paisagem através da fotografia. Algumas árvores de grande porte envolvidas por outras espécies de vegetação, o chão forrado por plantas rasteiras e folhas secas encobrindo pedras, a luz do sol projetando-se forte entre as copas das árvores favorecendo espaços de revelação e ocultação. Um lugar para performar e destacar a natureza, o meu corpo e a passagem do tempo. Um lugar para lançar questionamentos quanto a própria existência. Um lugar para revelar que as transformações físicas acontecem conosco, somos mutantes, não somos perenes.

Os procedimentos para a ação performática foram brevemente decididos e alguns cuidados tomados pela fragilidade do objeto. Num tempo relativamente curto, a fotógrafa buscando a melhor luz, a melhor distância e ângulo, eu me posicionando e pensando sobre tudo aquilo que estava acontecendo ali, o que eu via em minha volta, o que via no espelho, o que o espelho refletia, o que não era visto, mas se revelaria nas fotografias.

As imagens no visor da máquina fotográfica, e depois, abertas na tela do computador abriram muitas frentes sensíveis para o meu performar. Ali visíveis revelando o que está além do tempo vivido em meio à natureza, as fotografias cúmplices do espelho, como ele, multiplicando imagens. $\mathrm{O}$ espelho nos mostra como somos em imagem, somos ali "pura imagem", extraídos do nosso corpo, "fazendo nossa aparência existir fora de nós, fora de nosso corpo e for a de nossa alma." (COCCIA, 2010, p.21) 


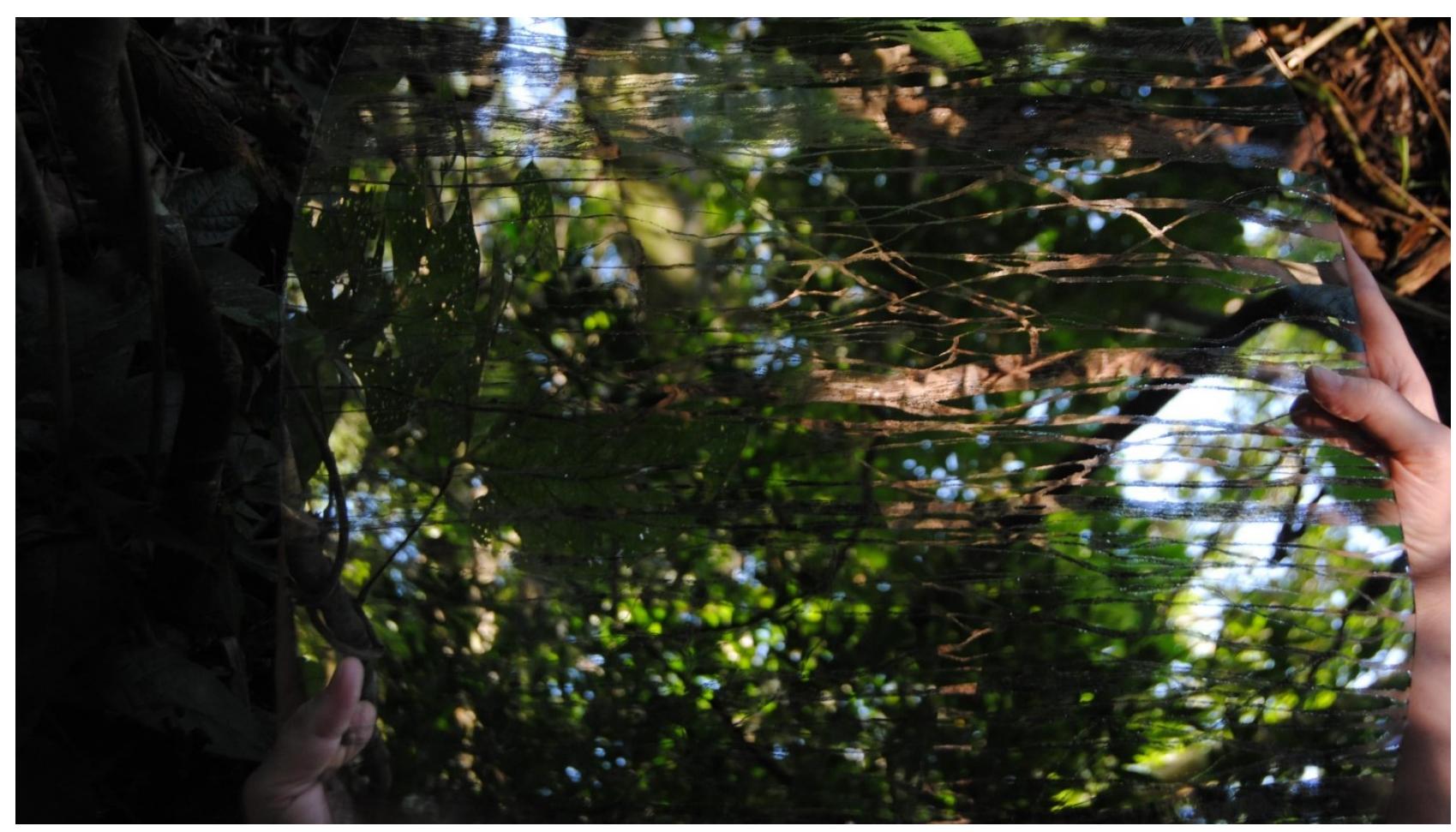

Figura 1. Sandra Correia Favero, Em meio a natureza, fora do corpo, pura imagem, série foto performance, acervo da autora, Florianópolis, 2021. Crédito fotográfico: Carolina Favero. 


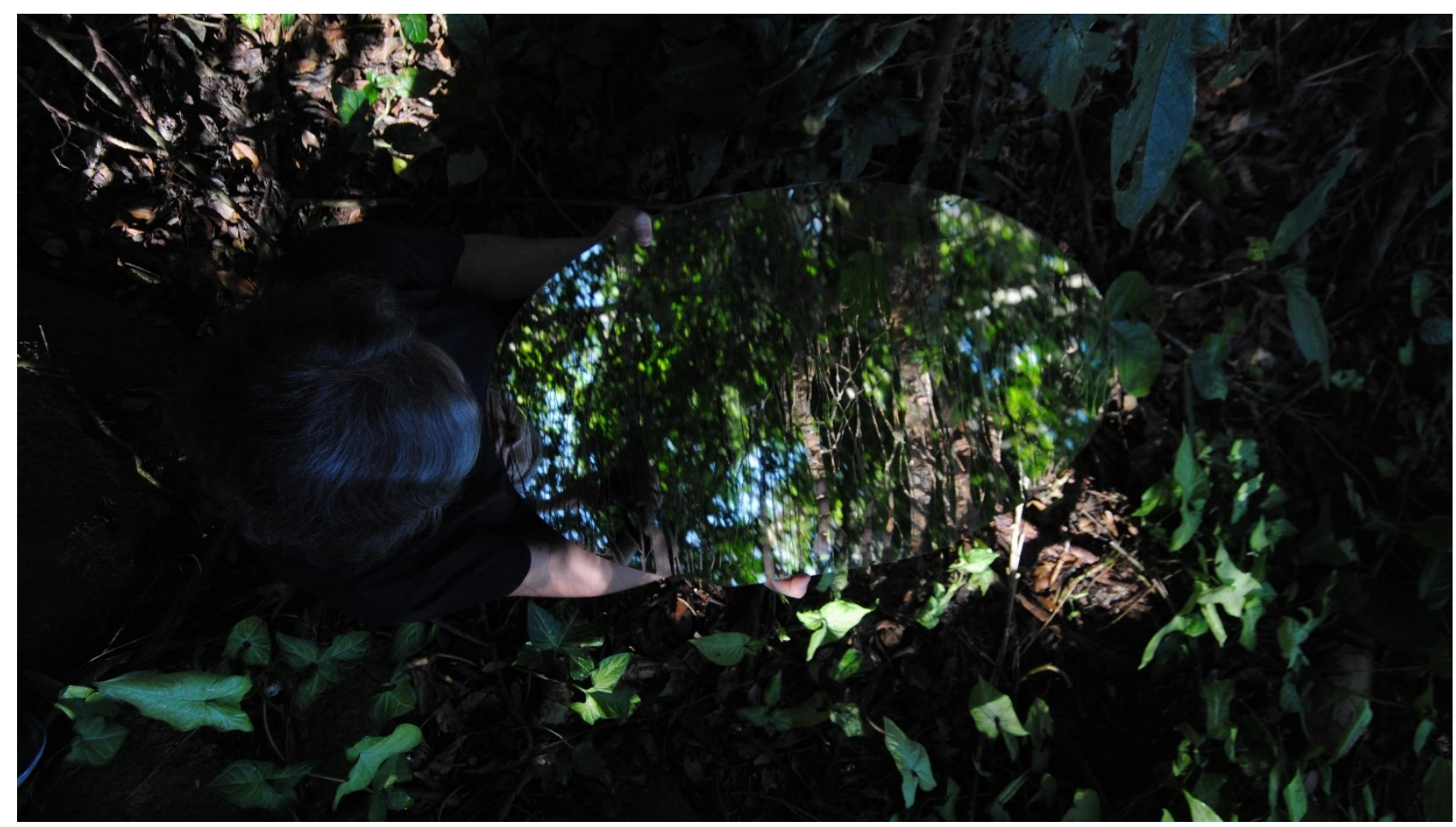

Figura 2. Sandra Correia Favero, Em meio a natureza, fora do corpo, pura imagem, série foto performance, acervo da autora, Florianópolis, 2021. Crédito fotográfico: Carolina Favero. 


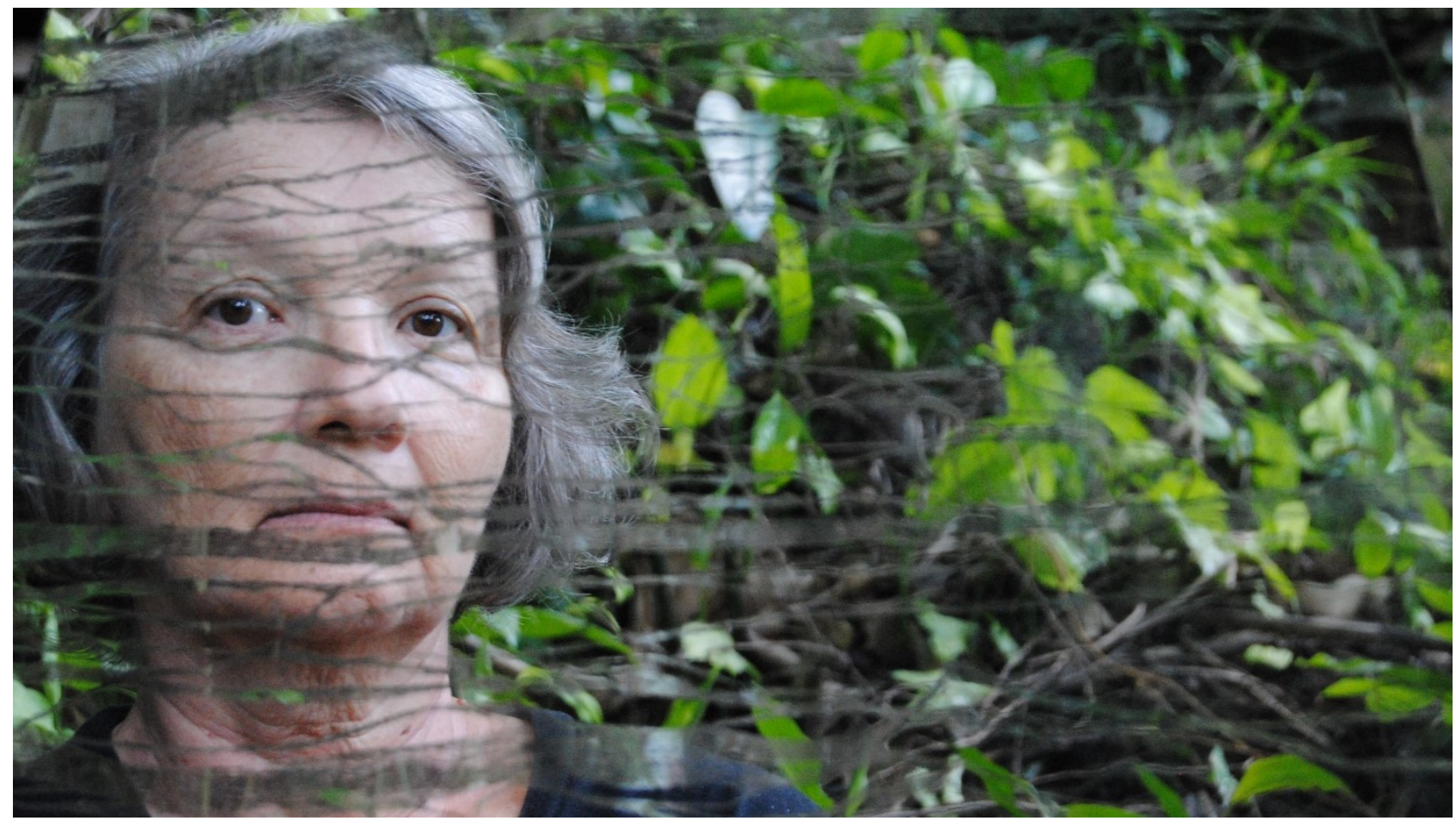

Figura 3. Sandra Correia Favero, Em meio a natureza, fora do corpo, pura imagem, série foto performance, acervo da autora, Florianópolis, 2021. Crédito fotográfico: Carolina Favero. 


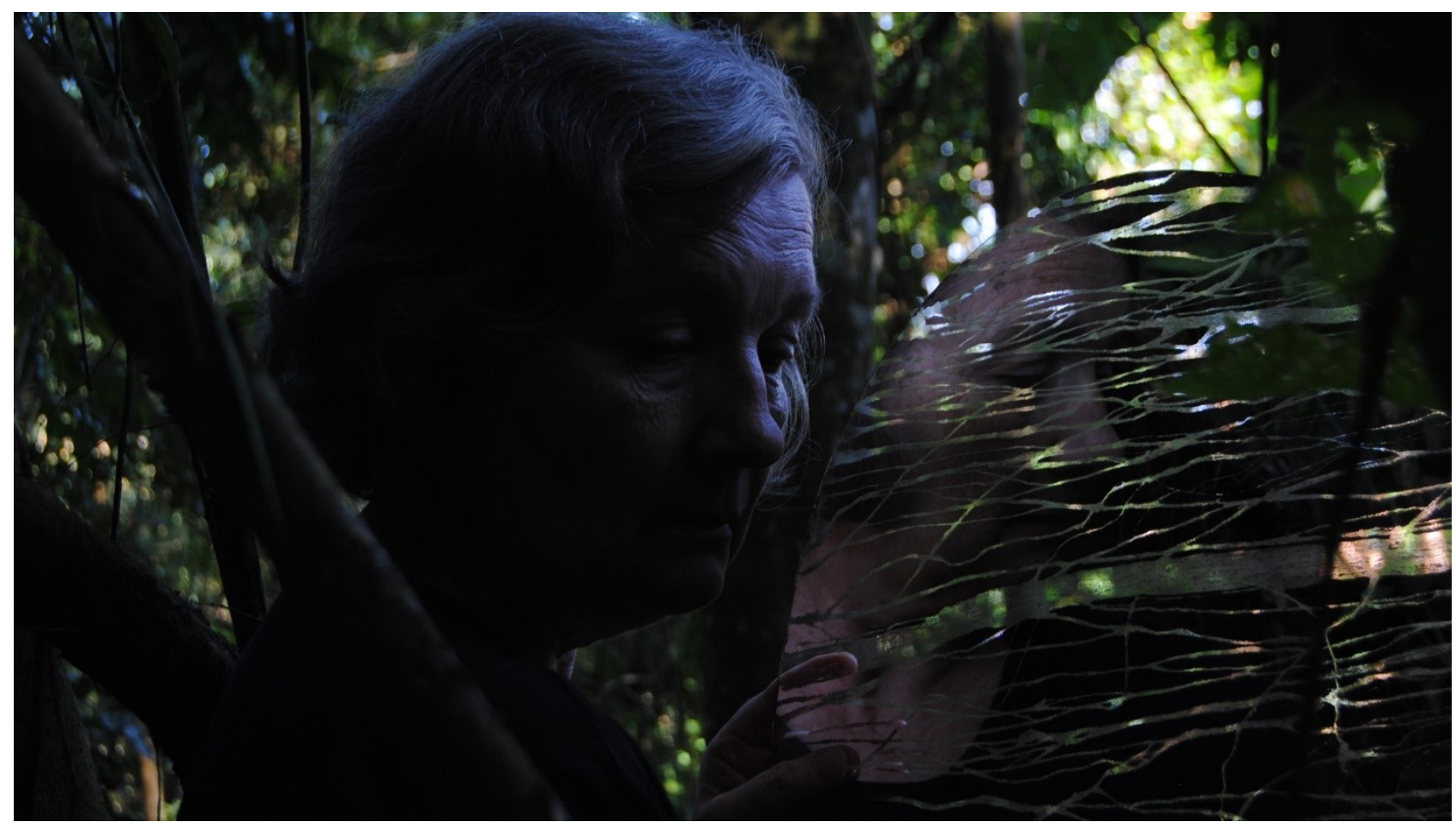

Figura 4. Sandra Correia Favero, Em meio a natureza, fora do corpo, pura imagem, série foto performance, acervo da autora, Florianópolis, 2021. Crédito fotográfico: Carolina Favero. 


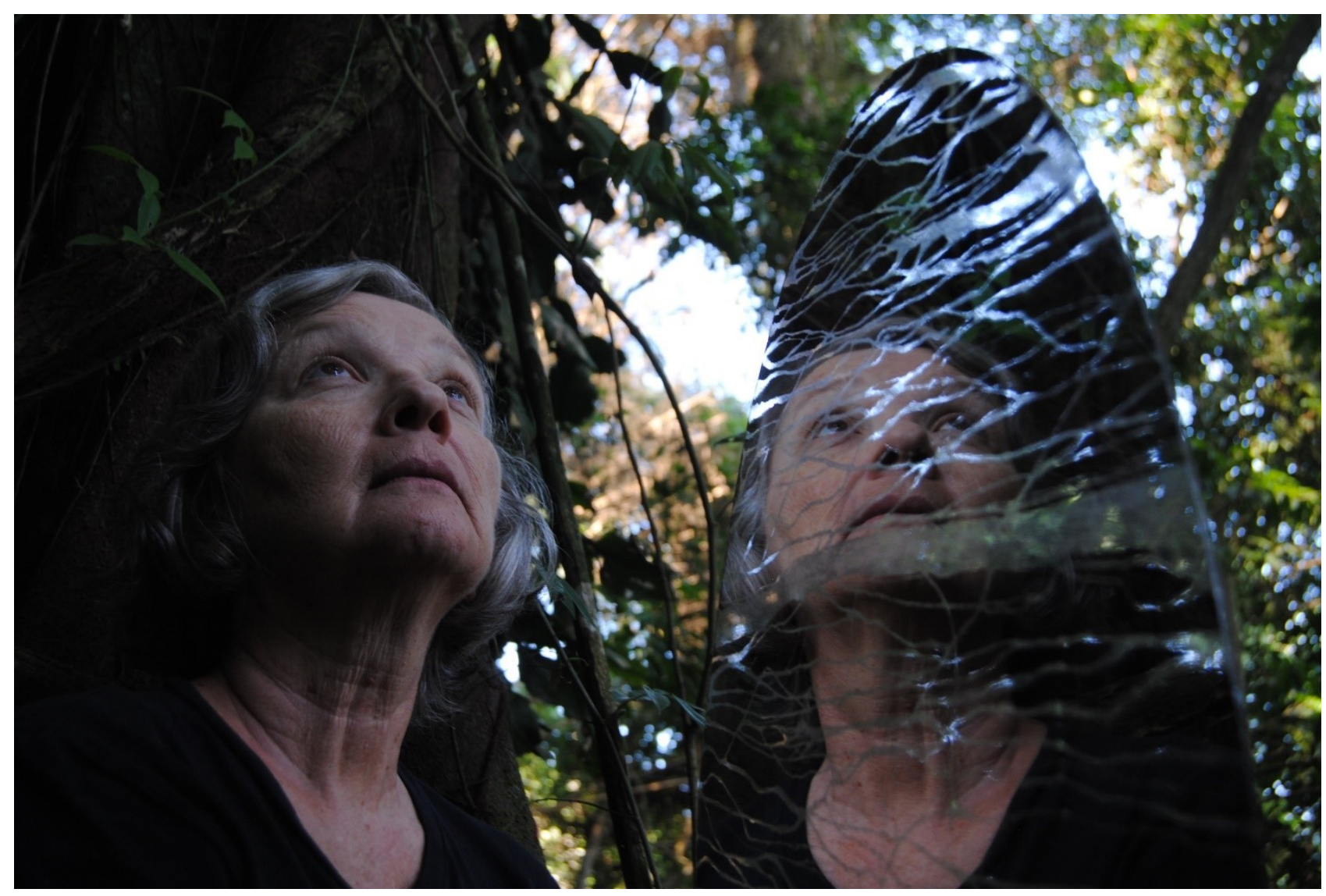

Figura 5. Sandra Correia Favero, Em meio a natureza, fora do corpo, pura imagem, série foto performance, acervo da autora, Florianópolis, 2021. Crédito fotográfico: Carolina Favero. 


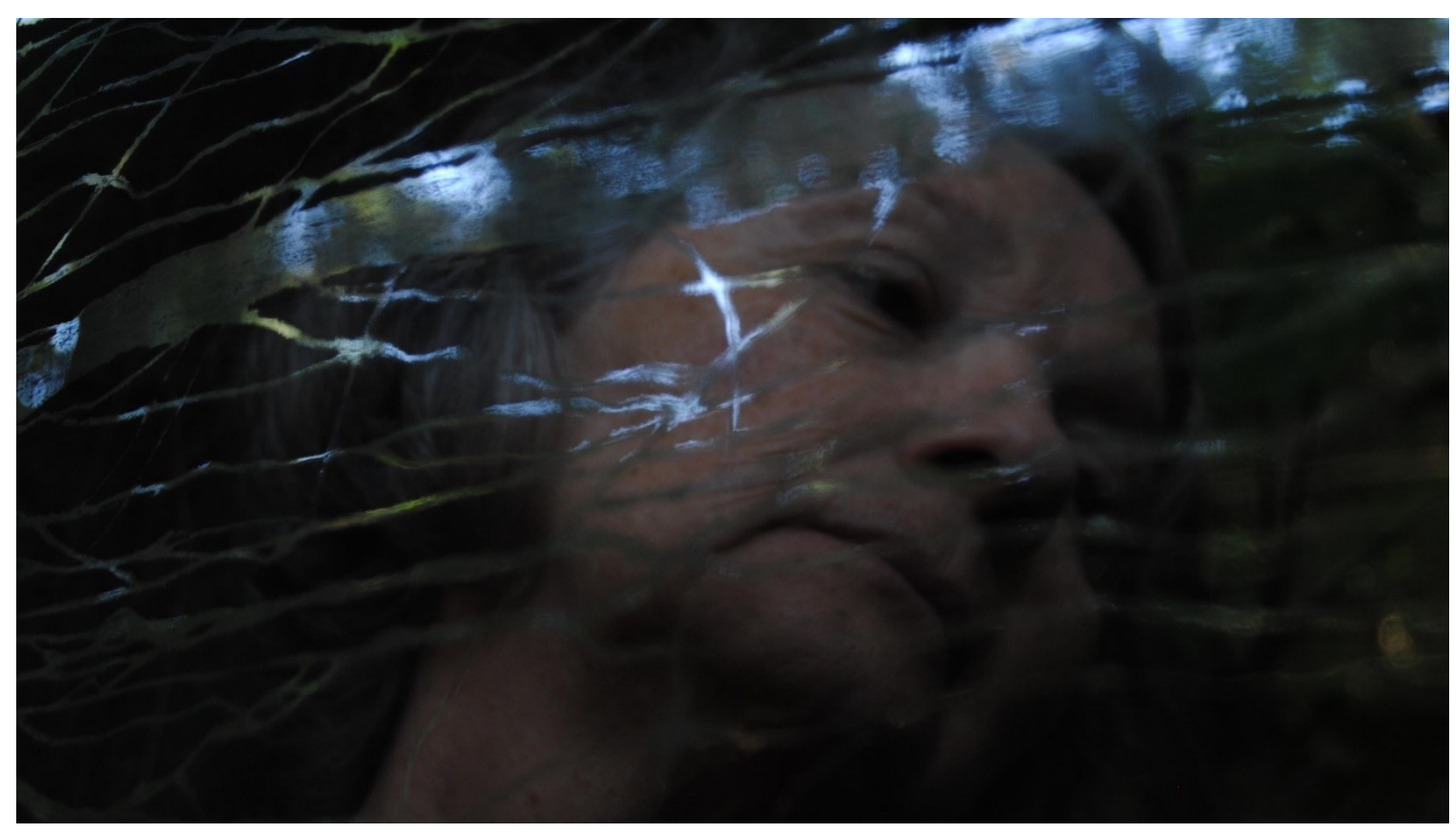

Figura 6. Sandra Correia Favero, Em meio a natureza, fora do corpo, pura imagem, série foto performance, acervo da autora, Florianópolis, 2021. Crédito fotográfico: Carolina Favero. 


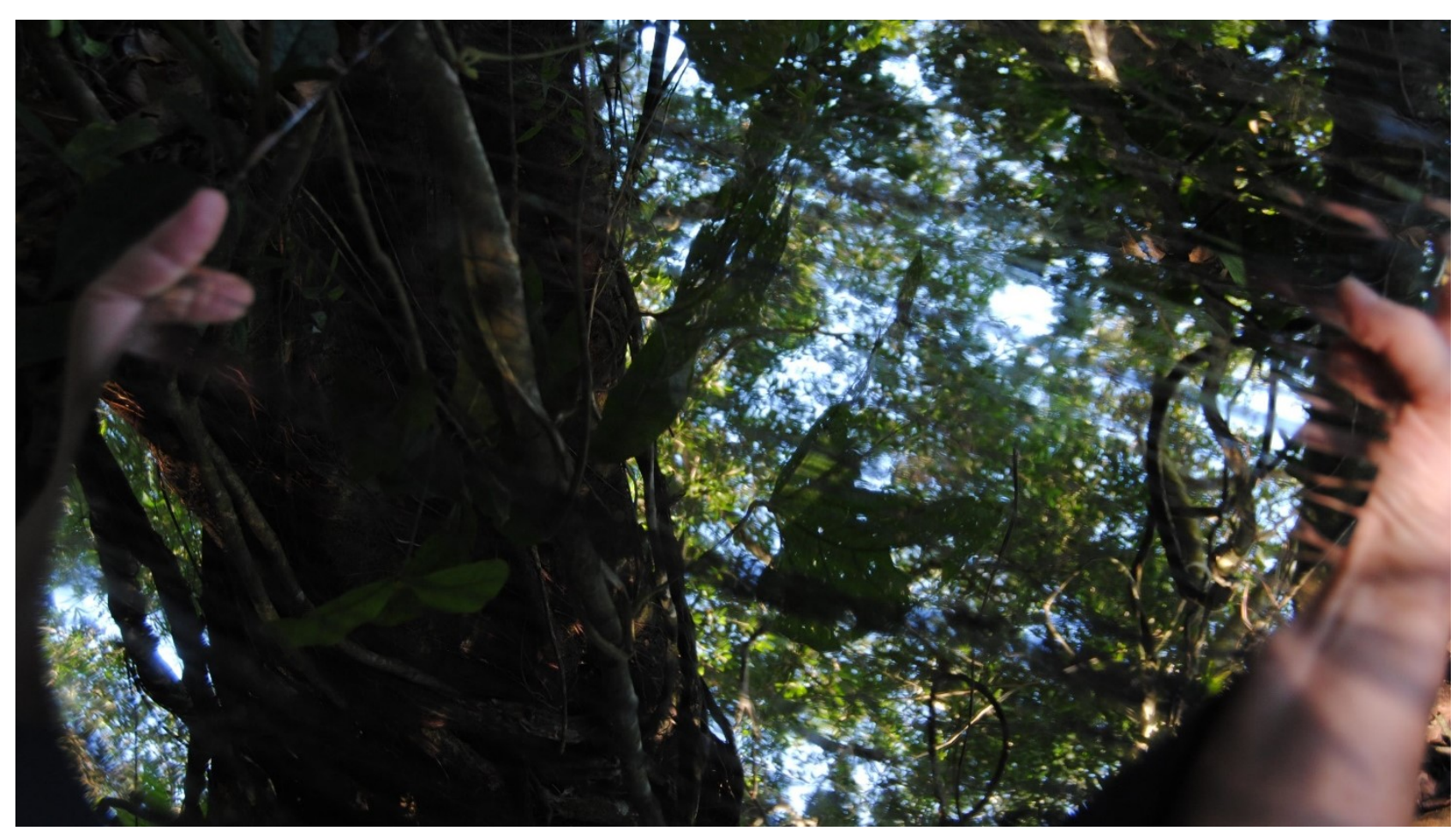

Figura 7. Sandra Correia Favero, Em meio a natureza, fora do corpo, pura imagem, série foto performance, acervo da autora, Florianópolis, 2021. Crédito fotográfico: Carolina Favero. 


\section{Referências}

COCCIA, Emanuele. A vida sensível. Florianópolis: Cultura e Barbárie, 2010.

. A vidas das plantas. Florianópolis: Cultura e Barbárie, 2018.

R. Inter. Interdisc. Art\&Sensorium, Curitiba, v.8, n.2, p. 261 - 270 Jul.- Dez. 2021 